\title{
Characterizing physics students' ethical reasoning after a unit on the development of the atomic bomb
}

\author{
Egla Ochoa-Madrid, Alice Olmstead, and Brianne Gutmann \\ Department of Physics, Texas State University, 749 N. Comanche Street, San Marcos, TX, USA, 78666
}

The societal implications of technology developed through physics research are not always clear. Physicists need to use ethical reasoning skills to maneuver through morally ambiguous situations. For this reason, curricula for physics students should also be geared towards developing these skills. Research can be found on the effects of structured ethical discussions in similar fields like engineering education, however, little research can be found on their effects in physics education. Our research focuses on how students interpret and apply an ethical framework to discussions about the development of the atomic bomb and to current STEM research. Our preliminary analysis shows that students conflate certain ethical principles and/or avoid their negative implications, which in turn leads to a misapplication of the principles. However, students also demonstrate a range of productive approaches to applying these ethical principles which contribute to the development of strong ethical arguments. 


\section{Introduction}

Some of the great, progressive thinkers of our time [1,2] have criticized educational systems and envisioned radically different alternatives. Freire [1] denounces typical education as a "banking system" where students receive, organize, and store deposits of knowledge. He argues that this banking system maintains oppressive structures, by treating students as beings to be managed, and discouraging them from thinking critically about the purpose of this knowledge. Instead, he argues, we should "abandon the educational goal of depositmaking and replace it with the posing of problems of human beings and their relations with the world" (Ref. [1] p. 79).

While it would be difficult to achieve the level of radical change Freire proposes in a typical undergraduate physics classroom, we think that PER can and should do more to move in this direction. PER, Physics Education Research, has positively impacted the level and extent of student discourse in many physics classes [3]. However, much more work could be done within PER to critically examine the scope of the content taught in physics classes and consider how expanding this scope could empower students (see [4], for one example). Much of PER focuses on helping students learn a fairly constrained set of "standard" content [5]. While learning this content can be important, it does little to help students assess the complex social and political consequences of decisions they will make during their careers.

The tools of STEM could be used to address existential threats like global climate change, and emerging physicists can play a role in this work [6]. Yet scientific innovation does not always advance desirable outcomes for all people, and can instead harm already vulnerable groups [7]. Students will also likely encounter subtle and overt pressure from the military, corporations, and governments that all have agendas in mind [8]. Thus, navigating real-world decisions with integrity [8] will pose challenges for students that typical physics curricula do not prepare them to confront.

We argue that physics instructors should support students in learning to critically examine the role of STEM innovations in society, and that PER should better support this kind of instructional design. Our goal is not to dictate the conclusions students will arrive at, but rather to help students strengthen their ability to make well-informed career decisions and to validate the importance of ethical reasoning. Our stance aligns strongly with the growing focus on ethics within engineering education and education research [9]. In contrast, while the physics community does discuss ethics at the professional level, the scope of these conversations is much narrower [10]. We agree with proponents of discipline-based education research that it is useful to both draw on work from other disciplines and to generate insights in disciplinary contexts [11].

Our current work examines how physics students engage with a curricular unit on the history and ethics of developing the atomic bomb. The 2nd author developed and implemented this unit in a Modern Physics class at Texas State Uni- versity. In this paper, we start to unpack students' reasoning. We address the research question: How do physics students interpret and apply an ethical framework to the development of the atomic bomb and other STEM examples?

\section{Literature review}

Our study builds on a growing body of literature that explores how engineering students learn about ethics and what instructional strategies may be best suited for teaching ethical reasoning skills to engineers [9, 12-20].

In alignment with the ABET accreditation standards, many engineering departments now include ethics as a required part of the curriculum [9]. This has presented a variety of instructional models and examples of student engagement to study [9, 21]. Meta-analyses of these programs identify that ethics is often addressed through stand-alone courses, modules within required courses, or a hybrid [13-15, 17, 18], which primarily draw from ethics codes and case studies $[15,17]$. The scope of ethical instruction can be classified as microethics (interactions with others in the field, such as professional conduct) or macroethics (consideration of the impact on society and the profession as a whole) [22]. While many programs focus on microethics [19], there has been some push to include macroethics $[13,16,18]$.

A number of models for evaluating and defining relevant skills for ethical reasoning have emerged from literature. For example, Kohlberg created a framework with different stages and levels of moral reasoning [23]. Rest expanded on this framework to stress skills like moral sensitivity, judgment, motivation, and character and implementation (courage to implement ethical decisions) [24]. Similarly, May and Luth focus on skills like perspective-taking, moral efficacy, moral courage, and moral meaningfulness [25]. Others use Azjen's theory of planned behavior [26] to identify pressures that may influence students' ability to act on their morals [27, 28].

Hess et al.'s research on students' learning about ethics [29] is particularly relevant for this study, as we adapted their pedagogical framework and resources when designing the curricular unit considered here. The authors designed and studied the outcomes of an engineering ethics course. Hess et al. take the stance that ethical reasoning is closely tied with the development of empathy. They also argue that perspective-taking , a cognitive process, is the key driver for this kind of development. The goal of the course then was to guide students to develop perspective-taking skills, even if this might not change students' own views about the ethical issues discussed.

Each of the curricular units in Hess et al.'s course used the same framework for "Scaffolded, Interactive, and Reflective Analysis" (SIRA) [29-31]. In this framework, students are introduced to a controversial topic using fact-based artifacts such as first-hand accounts, expert reports, and case scenarios. They are asked to reflect on their own perspectives and identify stakeholders' perspectives through moderated discussions with their peers. Students are also provided with Beauchamp's article, the "Four Principles of Health Care 
Ethics," [32] which serves as a critical component of the scaffolding in SIRA. According to Beauchamp, all ethical decisions are made by specifying and considering one's own views about the relative importance of four "universal" principles: respect for autonomy, nonmaleficence, beneficence, and justice (Table I). This ethical framework allows competing conclusions to be drawn from the same set of evidence, depending on the relative value placed in various stakeholders and principles.

Hess et al. interviewed students to better understand why and how their perspective-taking skills may have changed during the course. They find that students perceive listening to diverse perspectives during class, working through challenging, ambiguous ethical cases, and imagining the views of multiple stakeholders as important aspects of the course. They also find that students became more open-minded, felt they could consider situations more holistically, improved their ability to apply the four principles, and experienced broadening of their worldviews.

By adapting Hess et al.'s pedagogical strategy, we may replicate some of the positive outcomes they observe. But we also note that our instructional context is significantly different, and therefore we do not assume that this will occur. The students in Ref. [29] were biomedical engineers, and they engaged in the same reflective process multiple times. Thus, there is much to be discovered about happens when such a unit is implemented once in a physics class. We describe our current approach to this research in the following section.

\section{Methods}

\section{A. Classroom context}

Students in this study were enrolled in a Modern Physics class during Spring 2019. The class included 23 students $(36 \%$ women, $64 \%$ men; $50 \%$ white, 36\% Hispanic/Latinx, $14 \%$ both Hispanic/Latinx and white), as well as three male instructional assistants ( 2 white, 1 Hispanic/Latinx) and a white female professor (the 2nd author). As part of a larger unit on nuclear physics (fission, fusion, nuclear stability, and nuclear ethics), students were guided through a 2-week discussion on the development of the atomic bomb. Student groups completed an in-class worksheet that asked them to establish a timeline of key events and people in the history of the atomic bomb development, and to consider Beauchamp's framework for ethical reasoning. Students were then asked to apply the ethical framework to letters and documents from key figures. Outside of class, students were asked to read Beauchamp's "Four Principles" [32] and several letters from "The Manhattan Project: The Birth of the Atomic Bomb in the Words of Its Creators, Eyewitnesses, and Historians" [33] to build up their knowledge of relevant history and this ethical framework. On the last day of the unit, students were asked to generate a list of current STEM examples to which the ethical framework could be applied.

\section{B. Analytic approach}

We collected video-recordings of students' in-class conversations and documented their homework and exam responses during this unit. For this paper, we're choosing to focus on students' written responses to the following exam questions:

1. Consider a stance that a physicist or world leader took related to the development of the atomic bomb. I. Describe the example that you are thinking of. Who took this stance, when were they thinking about this relative to other key events, and what was their alignment? II. In what ways does this argument align with one or more of the four ethical principles that we have discussed in class? State the principles and explain your reasoning.

2. Provide an example of current scientific research to which the four ethical principles could be applied. What is an argument that someone could make for or against this research, and how does that argument align with one or more of the four principles?

Students' written responses to these questions seemed likely to demonstrate how individual students understand each of Beauchamp's four principles, and how they apply the principles to various situations. Responses to these questions also seemed likely to showcase some aspects of students' perspective-taking skills.

In our analysis, we look for trends in how students use each of the principles individually. We strive to foreground the ideas that students articulate before considering whether they used the "correct" terms to describe those ideas. We also strive to focus on how students' reasoning helps them to build persuasive ethical arguments, as well as what limits these arguments. Although we did not observe this in our data, we left open the possibility that students could make persuasive arguments without using this specific framework.

\section{Results}

Table I shows the general trends we observed in student responses, including productive and limited applications for each principle. We elaborate on these trends below.

\section{A. Respect for autonomy}

Essentially all students who use respect for autonomy seem to understand that it involves choice by stakeholders. Students who apply the principle particularly well also seem to understand what it means to facilitate these choices. For example, one student applies respect for autonomy to consider how Einstein enables FDR and other members of Congress to make an informed decision about the atomic bomb:

“Einstein's advocacy... aligns with the principle of respect for autonomy... By encouraging communication between policy makers and scientists each group has 


\begin{tabular}{|c|c|c|c|}
\hline Principle & Brief definition from [32] & Characteristics of productive applications & Characteristics of limited applications \\
\hline $\begin{array}{l}\text { Respect for } \\
\text { Autonomy }\end{array}$ & $\begin{array}{l}\text { Enable stakeholders to } \\
\text { make informed decisions }\end{array}$ & $\begin{array}{l}\text { Describing how decision-makers share key } \\
\text { information and seek others' input before } \\
\text { acting }\end{array}$ & $\begin{array}{l}\text { Inaccurately describing how a decision-maker } \\
\text { can deny/restrict others' actions }\end{array}$ \\
\hline $\begin{array}{l}\text { Non- } \\
\text { maleficence }\end{array}$ & Do no harm & $\begin{array}{l}\text { Stating that harm will not be caused, or } \\
\text { acknowledging possible harm and using } \\
\text { nonmaleficence as a counter-argument }\end{array}$ & $\begin{array}{l}\text { Using nonmaleficence to support and identify } \\
\text { the benefits of a decision that involves possible } \\
\text { or likely harm; conflating with beneficence }\end{array}$ \\
\hline Beneficence & $\begin{array}{l}\text { Maximize benefits, } \\
\text { minimize harm }\end{array}$ & $\begin{array}{l}\text { Identifying likely benefits of a decision; } \\
\text { sometimes identifying likely risks }\end{array}$ & $\begin{array}{l}\text { Omitting previously-identified stakeholders } \\
\text { who could experience harm; not discussing } \\
\text { potential risks generally }\end{array}$ \\
\hline Justice & Treat equals equally & $\begin{array}{l}\text { Identifying how benefits and risks could be } \\
\text { distributed among specific stakeholder groups, } \\
\text { and why }\end{array}$ & $\begin{array}{l}\text { Using "justice" to be synonymous with the } \\
\text { moral values or desires of a decision-maker } \\
\text { (e.g., fairness, honesty, objectivity) without } \\
\text { further specification of stakeholders; conflating } \\
\text { with respect for autonomy }\end{array}$ \\
\hline
\end{tabular}

TABLE I. Beauchamp's four ethical principles, along with observed trends of productive and limited student applications.

more autonomy and ability to contribute to high-stakes decisions because they are all better informed."

Here, the student notes that Einstein enables FDR to make an informed decision by providing insight into the effects of the bomb. By doing this, the student considers the perspectives of Einstein and FDR as stakeholders in this decision.

A second student considers Einstein's intention in writing to FDR when applying respect for autonomy. They write:

"Respect for Autonomy - [Einstein] wasn't forcing [the government] to act on his suggestions."

This student also recognizes that Einstein had at least some influence in how this decision was made. However, the second student's response also showcases a common point of confusion by stating that Einstein "wasn't forcing" anyone to act in any way. This limits the student's argument for Einstein's intentions in this context. Other students also describe Einstein and other scientists involved in the atomic development as "allowing" politicians to make their own decisions.

\section{B. Nonmaleficence}

Most students seem to understand that nonmaleficence stresses the importance of avoiding harm at all costs. Students who are particularly adept at applying nonmaleficence seem to recognize that this principle is absolute, in that no harm can be caused without creating inconsistency with the principle. One student strongly takes up this idea to suggest that stopping the development of artificial intelligence (until it is better understood) would prevent harm from biases:

\footnotetext{
"[A]pplications of deep learning algorithms have been known to have inherit biases from their data sets... the development of new technology in this area should be slowed down until solutions are arrived to prevent doing harm (nonmaleficence)."
}

In the context of their full response, this student cleanly articulates what the principle of nonmaleficence suggests as a decision path for the development of artificial intelligence, even while considering other decisions that prioritize beneficence.

However, there is evidence that students confuse the extent to which nonmaleficence means "do no harm," instead interpreting it to mean "minimize harm." This use conflates nonmaleficence with parts of beneficence. For example, one student states:

\section{"FDR was pushing to create the bomb to maximize the benefits for his country and the allies... How is that bomb created without the intention of evil? Simple. The U.S needed to show their "muscle"... The bomb was deployed to stop the war. Wouldn't it have been evil to keep the war going?"}

Like the previous student, this student recognizes the risk that their technology poses. They contemplate the creation and use of the bomb and how this came about "without the intention of evil" because ultimately it would stop the war. However, the student also describes deploying the bomb, which we, and likely the student, interpret as causing obvious harm. Instead of arguing that this stance goes against nonmaleficence by doing some harm, they argue that it aligns with nonmaleficence because it minimizes the "evil."

\section{Beneficence}

Most students reflect on both parts of beneficence: maximizing benefits and minimizing harm. The strongest applications of this principle also follow through on both ideas for multiple stakeholders and articulate a sense of prioritization. For example, one student states how FDR seems to have considered and prioritized the benefits to Americans relative to the harm to Japanese civilians:

"[FDR] would have rather obliterated the cities of Japan with the bomb than have risked the lives of po- 
tentially millions of Americans doing a land-based invasion. He was trying to do more good than harm... as he did have to weigh in the fact that hundred of thousands of Japanese civilians would have been killed. But this was for the benefit of saving U.S. lives."

Carrying this principle through in this way creates a consistent argument and demonstrate a thorough practice of perspective taking skills. In contrast, a different student, who considers the ethics of self-driving trucks, identifies truck drivers as stakeholders early in their response, but does not acknowledge them in their application of beneficence:

"Non-maleficence: Self driving trucks are smarter than human drivers and do not suffer fatigue... Beneficence: ...Producers will receive data on their trucks' activity... Consumers will benefit from reduced insurance and liability."

Here, the student does not acknowledge the risks of selfdriving trucks to the careers of human drivers in their application of beneficence. This example also shows a pattern where some students avoid the negative aspects of beneficence.

\section{Justice}

There are a variety of approaches to applying this principle. Some students demonstrate a strong understanding of justice by describing how advantages and disadvantages are distributed among stakeholders. As an example, the student who writes about artificial intelligence presents the implications of biases in deep learning algorithms for justice:

"[T]his whole issue [of deep learning algorithms] rests on issues of justice, as one of the deepest worries is machines learning human biases from their data sets, which will unfairly harm several groups of people."

Here the student considers that this technology has likely negative effects for certain groups, and explicitly connects this to the idea of justice. They note that because of the biases that artificial intelligence tends to inherit, the benefits will not be equally distributed.

In contrast, other students do not discuss specific benefits and harms to stakeholders when considering justice. Instead, they apply justice in ways that seem tied to emotional responses and moral values. For example, one student takes Einstein's perspective as a refugee and describes justice as a reason he wrote to FDR:

"Albert Einstein wrote a letter to FDR informing him of the development of nuclear power where he tries to persuade him into gathering a team to develop this power before the Germans... Einstein was a refugee from Germany. He wanted justice from what Hitler was doing in Germany.”
Along similar lines, multiple other students only invoke the word "fairness" in their description of how an argument aligns with justice. Another student evokes the moral value of objectivity ("providing objective facts and only the truth") to develop their argument for alignment with justice.

Finally, some students confuse the definitions of justice and respect for autonomy. For example, when a student is describing the ethics of gene editing, they write:

"Justice-> would those being tested on get all the information and risks?”

In expressing concern for informed decision-making, the student applies the idea of respect for autonomy, not justice.

\section{Discussion \& Conclusions}

We find that following a 2-week unit on the ethics of the development of the atomic bomb, most physics students demonstrate facility with at least one of the four principles in Beauchamp's ethical framework (respect for autonomy, nonmaleficence, beneficence, and justice) and can use them to construct meaningful arguments. Using this framework, students were able to identify multiple stakeholders and the perspectives they might hold. We also identify several limitations in students' applications of these principles. These limitations include conflating nonmaleficence with beneficence and justice with respect for autonomy; inaccurately interpreting respect for autonomy; focusing on only positive aspects of beneficence; and using justice to characterize moral values without specifying stakeholders.

These results demonstrate that Beauchamp's ethical principles provide useful scaffolding for physics students to construct ethical arguments. Even in cases where students' reasoning is limited, we see the ideas behind the principles strengthening their responses. These results suggest that ethical frameworks generally may support student reasoning, and that it can be fruitful to adapt engineering ethics curricula for physics classes.

This study represents an important step towards understanding how to support physics students in learning about ethics. It also opens up avenues for future research that could better diagnose the learning processes of students engaging with ethics curricula. In particular, video analysis could provide valuable insights into why students construct particular kinds of responses, including potentially avoiding uncomfortable conclusions. We encourage others to build on this study to improve our community's understanding of how to incorporate ethics into physics instruction.

\section{Acknowledgments}

The authors thank the TXST PER group and the students who participated in the study. 
[1] P. Freire, pedagogy of the oppressed (Bloomberg Publishing Inc, New York, NY, 1970).

[2] b. hooks, Teaching to Transgress: Education as the Practice of Freedom (Routledge, New York, NY, 1994).

[3] C. Henderson, M. Dancy, and M. Niewiadomska-Bugaj, Physical Review Special Topics - Physics Education Research 8, 020104 (2012), ISSN 1554-9178, URL http://journals.aps.org/ prper/abstract/10.1103/PhysRevSTPER.8.020104.

[4] A. R. Daane, S. R. Decker, and V. Sawtelle, The Physics Teacher 55, 328 (2017), ISSN 0031-921X, URL http://aapt. scitation.org/doi/10.1119/1.4999724.

[5] S. R. Singer, N. R. Nielsen, H. A. Schweingruber, and others, Discipline-based education research: understanding and improving learning in undergraduate science and engineering (National Academies Press, 2012).

[6] President's Council of Advisors on Science and Technology, Tech. Rep., Washington, DC (2012).

[7] S. Harding, Objectivity and diversity: Another logic of scientific research (University of Chicago Press, 2015).

[8] E. Blue, M. Levine, and D. Nieusma, Engineering and War: Militarism, Ethics, Institutions, and Alternatives (Morgan and Claypool Publishers, 2013).

[9] National Academy of Engineering, Infusing Ethics into the Development of Engineers: Exemplary Education Activities and Programs (The National Academies Press, Washington, DC, 2016), ISBN 978-0-309-39085-9.

[10] K. Kirby and F. A. Houle, Physics Today 57, 42 (2004), URL http://physicstoday.scitation.org/doi/10.1063/1.1839376.

[11] C. Henderson, M. Connolly, E. L. Dolan, N. Finkelstein, S. Franklin, S. Malcom, C. Rasmussen, K. Redd, and K. St. John, Journal of Geoscience Education 65, 215 (2017), ISSN 1089-9995.

[12] L. L. Bucciarelli, European journal of engineering education 33, 141 (2008).

[13] H. Canary, J. Herkert, K. Ellison, and J. M. Wetmore (2012).

[14] A. Colby and W. M. Sullivan, Journal of Engineering Education 97, 327 (2008), ISSN 2168-9830.

[15] D. R. Haws, Journal of Engineering Education 90, 223 (2001), ISSN 2168-9830.

[16] D. R. Haws, Science and Engineering Ethics 10, 204 (2004), ISSN 1471-5546.

[17] J. R. Herkert, European journal of engineering education 25, 303 (2000).
[18] J. R. Herkert, Mediterranean Journal of Mathematics 11, 373 (2005), ISSN 1660-5446.

[19] J. Li and S. Fu, Science and Engineering Ethics 18, 339 (2012), ISSN 1471-5546.

[20] B. Newberry, Science and Engineering Ethics 10, 343 (2004), ISSN 1471-5546.

[21] R. D. Hollander, C. H. Fletcher, F. F. Benya, et al., Practical Guidance on Science and Engineering Ethics Education for Instructors and Administrators: Papers and Summary from a Workshop December 12, 2012 (National Academies Press, 2013).

[22] J. Ladd (Wadsworth Publ. Co, Belmont, CA, USA, 1985), pp. 8-13, ISBN 0-534-04257-0, URL http://dl.acm.org/citation. $\mathrm{cfm}$ ?id=2569.2570.

[23] L. Kohlberg, Essays on moral development, volume one: The philosophy of moral development (1981).

[24] J. R. Rest, DIT: Manual for the defining issues test (Center for the Study of Ethical Development, University of Minnesota, 1986).

[25] D. R. May and M. T. Luth, Science and Engineering Ethics 19, 545 (2013), ISSN 1471-5546.

[26] I. Ajzen, in Action control (Springer, 1985), pp. 11-39.

[27] T. S. Harding, D. D. Carpenter, and C. J. Finelli, Journal of Engineering Education 101, 346 (2012), ISSN 2168-9830.

[28] D. Bairaktarova and A. Woodcock, Science and Engineering Ethics 23, 1129 (2017), ISSN 1471-5546.

[29] J. L. Hess, J. Strobel, and A. O. Brightman, Journal of Engineering Education 106, 534 (2017), ISSN 10694730.

[30] L. Kisselburgh, C. Zoltowski, J. Beever, J. Hess, M. Krane, and A. Brightman, in 2013 IEEE Frontiers in Education Conference (FIE) (2013), pp. 1561-1563.

[31] L. G. Kisselburgh, J. L. Hess, C. B. Zoltowski, J. Beever, and A. O. Brightman, in 123rd ASEE Annual Conference \& Exposition, New Orleans, LA, USA, June 26 (2016), vol. 29.

[32] T. L. Beauchamp, in Principles of Health Care Ethics (John Wiley \& Sons, Ltd, 2007), pp. 3-10, ISBN 9780470510544.

[33] C. C. Kelly and R. Rhodes, The Manhattan Project: The Birth of the Atomic Bomb in the Words of Its Creators, Eyewitnesses, and Historians (Black Dog \& Leventhal Publishers, Incorporated, 2009), ISBN 9781579128081, URL https: //books.google.com/books?id=fLtZluUeWFgC. 